\title{
BMJ Open Organisational context of hospitals that participated in a multi-site mentored medication reconciliation quality improvement project (MARQUIS2): a cross-sectional observational study
}

\author{
Deonni P Stolldorf (10) ,, Jeffrey L Schnipper, ${ }^{3,4}$ Amanda S Mixon, ,2,5,6 \\ Mary Dietrich, ${ }^{1,7}$ Sunil Kripalani ${ }^{2,5}$
}

To cite: Stolldorf DP, Schnipper JL, Mixon AS, et al. Organisational context of hospitals that participated in a multi-site mentored medication reconciliation quality improvement project (MARQUIS2): a cross-sectional observational study. BMJ Open 2019;9:e030834. doi:10.1136/ bmjopen-2019-030834

- Prepublication history for this paper is available online. To view these files please visit the journal online (http://dx.doi org/10.1136/bmjopen-2019030834).

Received 03 April 2019 Revised 16 August 2019 Accepted 23 September 2019

Check for updates

(C) Author(s) (or their employer(s)) 2019. Re-use permitted under CC BY-NC. No commercial re-use. See rights and permissions. Published by BMJ.

For numbered affiliations see end of article.

Correspondence to

Dr Deonni P Stolldorf;

deonni.stolldorf@vanderbilt.edu

\section{ABSTRACT}

Objectives Medication reconciliation (MedRec) is an important patient safety strategy and is widespread in US hospitals and globally. Nevertheless, high quality MedRec has been difficult to implement. As part of a larger study investigating MedRec interventions, we evaluated and compared organisational contextual factors and team cohesion by hospital characteristics and implementation team members' profession to better understand the environmental context and its correlates during a multisite quality improvement (QI) initiative.

Design We conducted a cross-sectional observational study using a web survey (contextual factors) and a national hospital database (hospital characteristics). Setting Hospitals participating in the second Multi-Centre Medication Reconciliation Quality Improvement Study (MARQUIS2).

Participants Implementation team members of 18 participating MARQUIS2 hospitals.

Outcomes Primary outcome: contextual factor ratings (ie, organisational capacity, leadership support, goal alignment, staff involvement, patient safety climate and team cohesion). Secondary outcome: differences in contextual factors by hospital characteristics.

Results Fifty-five team members from the 18 participating hospitals completed the survey. Ratings of contextual factors differed significantly by domain $(p<0.001)$, with organisational capacity scoring the lowest (mean=4.0 out of 7.0 ) and perceived team cohesion and goal alignment scoring the highest (mean 6.0 out of 7.0). No statistically significant differences were observed in contextual factors by hospital characteristics $(p>0.05)$. Respondents in the pharmacy profession gave lower ratings of leadership support than did those in the nursing or other professions group $(p=0.01)$.

Conclusions Hospital size, type and location did not drive differences in contextual factors, suggesting that tailoring MedRec Ql implementation to hospital characteristics may not be necessary. Strong team cohesion suggests the use of interdisciplinary teams does not detract from cohesion when conducting mentored QI projects. Organisational leaders should particularly focus on supporting pharmacy services and addressing their concerns during MedRec Ql initiatives. Future research should correlate contextual

\section{Strengths and limitations of the study}

- Multi-centre quality improvement research study using a national sample of a diverse group of hospitals who received mentored implementation of a medication reconciliation best practices toolkit.

- Contextual factors assessment using valid and reliable measurement tools.

- Observational, cross-sectional design and selection of hospitals for participation limit generalisability.

- Convenience sample of the second Multi-Centre Medication Reconciliation Quality Improvement Study hospitals with a resultant small sample size may have resulted in response bias and limited statistical power.

factors with implementation success to inform how best to prepare sites to implement complex QI interventions such as MedRec.

\section{INTRODUCTION}

Unintentional medication discrepancies (UMDs), defined as unintentional differences in patients' medication regime, occur in more than $50 \%$ of hospitalised patients. ${ }^{1}$ Medication reconciliation (MedRec) identifies and corrects UMDs by documenting, comparing and verifying patients' medication lists across care transitions. ${ }^{23}$ MedRec generally consists of several steps including: (a) developing an accurate list of each patient's medications; (b) validating each medication, dose and frequency at the time of writing orders; (c) identifying and correcting unintentional discrepancies in orders; (d) documenting any intentional changes to the medication regimen and (e) communicating the updated list to the patient, caregivers and the next provider(s) of care. ${ }^{4}$ High quality MedRec can reduce $\mathrm{UMDs}^{5}{ }^{6}$ and prevent adverse 
drug events and potential patient harm. ${ }^{27}$ MedRec is a US National Patient Safety Goal (NPSG.03.05.06) ${ }^{8}$ and, in response, hospitals nationwide are implementing MedRec practices. ${ }^{8}$

During the Multi-Centre Medication Reconciliation Quality Improvement Study (now known as MARQUIS1), we developed and refined an evidence-based toolkit of MedRec interventions (called the MARQUIS toolkit) to assist hospitals in achieving robust MedRec practices. ${ }^{9-11}$ The MARQUIS toolkit included interventions from eight domains: obtaining a best possible medication history; clarifying clinical roles and responsibilities; conducting discharge MedRec and patient/caregiver counselling; risk-stratifying patients; improving health information technology (HIT); enhancing sources of medication information; identifying and correcting real-time medication discrepancies; and engaging stakeholders. Sites chose which interventions to adapt and adopt for their particular circumstances. MARQUIS1 reduced rates of total medication discrepancies, but results varied by site. ${ }^{12}$ In the current study, the 'Implementation of a Medication Reconciliation Toolkit to Improve Patient Safety' (HS023757) (also known as the second MultiCentre Medication Reconciliation Quality Improvement Study (MARQUIS2)), our research team engaged 18 hospitals in a multi-site implementation of the refined MARQUIS toolkit to enhance the quality of their MedRec programmes, taking lessons learnt from MARQUIS1 in terms of intervention design and implementation. ${ }^{11}$ During MARQUIS2, hospital leaders chose to implement various components of the refined MARQUIS toolkit with oversight by a distance mentor who was an expert in MedRec and quality improvement (QI) principles.

We have found that sites varied significantly in how they implemented the MARQUIS toolkit. Anecdotal evidence suggests implementation during MARQUIS2 was affected by variations in organisational context and hospital characteristics and team factors. In general, experts agree that the successful implementation of medication safety strategies should account for local contextual constraints in order to improve medication safety. ${ }^{13}$ However, it is unclear which contextual factors to consider and whether hospital characteristics and team factors contribute to contextual differences in hospitals implementing medication safety strategies. MARQUIS2 provided a unique opportunity to (a) describe the organisational context in a group of hospitals that implemented medication safety strategies and, (b) determine if variation in contextual factors existed due to hospital and team factors.

Research indicates variation in contextual factors exists among hospitals participating in multi-site QI work and that the local context, policies and culture could hamper implementation efforts. ${ }^{14-17}$ Contextual factors reported several contextual factors that could hinder QI processes and include organisational capacity and climate and leadership support ${ }^{18-22}$ and the alignment of the goals of the upcoming change with organisational priorities. ${ }^{2123-26}$ Yet, the influence of organisational context on the implementation of MedRec in hospitals during multisite QI initiatives like MARQUIS2 is unclear.

Evidence further indicates that teaching and large hospitals may not be as effective in programme implementation due to complex organisational structures and programme oversight that is spread out across multiple organisational units. ${ }^{27-29}$ On the other hand, smaller and rural hospitals may have fewer resources compared with larger, urban hospitals.

In addition, variation in implementation teams' composition and size is also likely between hospitals. Teams of individuals are often charged with the responsibility of implementing the newly adopted intervention, technology or process (hereafter called implementation teams). These teams are often interdisciplinary, which may make it difficult to work cohesively as a group during implementation efforts. Team cohesion, the degree to which team members work together to achieve their goals, ${ }^{1522}$ is known to be positively associated with team functioning and effectiveness and subsequently better patient outcomes. ${ }^{30-33}$ Yet, its role in MedRec QI efforts is unclear.

As part of an agency for healthcare research and quality (AHRQ)-funded study to investigate the implementation strategies used during MARQUIS2 and assess the sustainability of the MARQUIS toolkit, we conducted a baseline assessment of the context of participating hospitals and their implementation teams. The objectives for this manuscript are to (a) describe organisational contextual factors and team cohesion in hospitals that participated in MARQUIS2 and (b) compare organisational contextual factors and team cohesion by hospital characteristics and the profession of implementation team members. We sought to fill the above knowledge gaps and inform whether a future tailored implementation approach is necessary when multi-site QI initiatives are undertaken in organisations that differ in size, type or location. Furthermore, the findings will also provide hospital leaders with guidance on areas that may need special focus in future MedRec QI initiatives and if group cohesion needs special attention when implementation teams are interdisciplinary. This current study also complements work that is underway to link contextual factors and the use of implementation strategies as identified by Powell $e t a \vec{l}^{4}$ to develop guidelines for the tailoring of implementation to the local context.

\section{METHODS}

\section{Study design, setting and participants}

We conducted a cross-sectional observational study of implementation team members from 18 hospitals participating in MARQUIS2. These 18 hospitals were selected from 72 sites that applied to participate in MARQUIS2. Hospitals were selected for inclusion in MARQUIS2 to specifically vary in hospital size (number of hospital beds), hospital type (teaching and community) and hospital location (rural, suburban and urban areas). In 
addition, the MARQUIS2 research team selected sites meeting the following criteria (based on an application completed by all interested sites): (a) strong institutional support (ie, a letter or support from an executive champion); (b) a site leader with strong QI knowledge and experience; (c) an interdisciplinary implementation team with clearly defined roles; (d) hospital experience with successful patient safety and QI projects; (e) local support, including a dedicated pharmacist(s) to collect study-related data and (f) demonstrated intention to implement at least one intervention from the MARQUIS Toolkit. Hospitals that had already implemented two or more interventions from the original MARQUIS1 toolkit were excluded from the study. ${ }^{12}$

We collected self-reported data on hospital size and location and used a national hospital database (American Hospital Association, Chicago, Illinois) to determine teaching status (defined as a member of the Council of Teaching Hospitals and Health Systems). We expected that each hospital's implementation team would include various stakeholders and would represent staff members who were locally assigned to implement the MARQUIS toolkit in their hospitals. The size and composition of implementation teams varied across the 18 hospitals. Teams ranged from 3 to 12 members. All teams were interdisciplinary in nature. In general, teams were composed of physicians (eg, hospitalists and internal medicine), pharmacy staff (ie, clinical pharmacists, pharmacy managers or directors, chief pharmacy officers, QI clinical pharmacists), nursing (eg, registered nurses in clinical areas and in quality and safety), QI and safety staff (eg, patient safety officer and chief quality officer) and HIT staff.

\section{Study measures of contextual factors}

As the MARQUIS2 study started, we invited implementation team members to complete a survey specifically designed for this research study. The survey consisted of questions related to organisational structures and processes and team cohesion. Survey items were drawn from existing scales ${ }^{835} 36$ as well as items previously developed by the principal investigator (DPS) ${ }^{37}$ The research team reviewed the survey items once the existing scales and items were adapted to fit the study's MedRec context. Steps taken to limit potential bias in self-reported data included reassuring participants of the confidentiality of their responses, using neutral words in any question stems formulated specifically for the study, and including previously tested, valid and reliable instruments as study measures. ${ }^{38}$ For purposes of comparing the scores, individual item response options were converted to a 7-point Likert scale from $1=$ strongly disagree to $7=$ strongly agree prior to generating the measure scores.

\section{Organisational structures}

Fourteen items measured the organisational structures of organisational capacity, leadership and goal alignment. To measure organisational capacity, survey items from existing instruments were adapted from the Determinants of Implementation Behavior Questionnaire (DIBQ) instrument (one item),${ }^{35}$ the Program Sustainability Index (PSI) (funding subscale) (three items) $^{8}$ and the sustainability survey on organisational capacity (four items). ${ }^{37}$ Questions included, for example, Current funding is sufficient for implementing MedRec' and 'Staffing is sufficient for implementing MedRec'. The validity and reliability of the DIBQ, PSI and sustainability survey have been previously established. ${ }^{85}$ An average of the item responses was used to generate an overall composite score of organisational capacity. Up to two randomly missing item responses within the set of eight was allowed. In this study, the organisational capacity scores had internal consistency reliability of 0.92 (Cronbach's alpha).

Leadership support was measured by four items. Specifically, one item from the sustainability survey and three items of the DIBQ survey related to leadership support were adapted for use. Participants were asked to indicate if they could count on management support, if managers were helpful, and if management listened to their concerns. A leadership support score was generated by averaging the four item responses; no missing item responses were allowed. The scores in this study had a Cronbach's alpha of 0.91 .

Goal alignment was measured using the sustainability survey items on goal alignment (five items, adapted). ${ }^{37}$ Questions asked about how much the MARQUIS2 goals were consistent with the overall hospital goals and if goals were credible to hospital administration and nurse executives. A goal alignment score was generated by averaging at least four of the composite five item responses. The scores in this study had a Cronbach's alpha of 0.83 .

\section{Organisational processes}

Staff involvement was measured using three items from the previously developed Correlates of Perceived Sustainability. ${ }^{36}$ Questions asked staff about information sharing and involvement in implementation. Scores were averaged across the three items. The internal consistency of the Perceived Cohesion Scale (PCS) in this study was good (Cronbach's alpha 0.78). Organisational climate was measured by 10 items from the AHRQ Hospital Survey on Patient Safety (HSPS). ${ }^{16} 2029$ The domains include organisational learning (three items), management support for patient safety (three items) and an overall perception of safety (four items). An average of the responses to the items comprising each domain was generated, as well as an average of all item responses to generate an overall score. A higher value for each of these scores indicates higher levels of support and climate for patient safety. The validity and reliability of AHRQ's HSPS have been reported elsewhere. ${ }^{2639}$

\section{Team characteristics}

Team cohesion was measured using PCS. ${ }^{22}$ We defined team cohesion as each team members' sense of 
belonging to the group responsible for implementing the MARQUIS2 toolkit and their feelings of morale associated with membership in the group. The PCS consists of 6 items that together measure morale (three items) and belonging (three items). The validity and reliability of the PCS have been reported elsewhere. ${ }^{40}$ A team cohesion score was generated by averaging at least five of the composite six item responses. The Cronbach's alpha of the scores in this sample was 0.95 .

\section{Patient and public involvement}

Patients or community members were not involved in this study as the study focus was to investigatethe organisational context of hospitals participating in the MARQUIS2 study. However, during the main MARQUIS2 study, a Patient and Family Advisory Council (PFAC) participated in monthly phone meetings and in all aspects of the MARQUIS2 study (eg, study design, data collection, interpretation, dissemination and study implications). The PFAC members were patients or caregivers with experiences related to medication safety (eg, experienced an adverse drug event during a care transition).

\section{Data analysis}

Data analyses were conducted using IBM SPSS Statistics (V.24, IBM Corporation). Complete data were available for all hospital-level and individual-level variables in this sample. Frequency distributions summarised the nominal and ordinal hospital and respondents' characteristics. Mean and SD summarised the normally distributed hospital level contextual factor scores. Due to small samples and skewness, the median, minimum and maximum responses were used to summarise the subgroups of hospitals and professional groups. Mixed-level general linear analysis (controlling for the correlations within hospitals) was used to test for differences among the hospital-level contextual factor responses. Mann-Whitney and Kruskal-Wallis tests compared responses by hospital characteristics and respondent professional group. With the exception of post hoc tests, which used Bonferronicorrected alpha levels, a two-sided alpha of 0.05 was used for determining statistical significance.

\section{RESULTS}

\section{Sample characteristics}

A total of 55 staff members from the 18 participating hospitals completed the survey (66\% response rate). Respondents per hospital ranged from one $(n=4,22.2 \%)$ to five $(\mathrm{n}=2,11.1 \%)$. As shown in table 1 , slightly more than half of the hospitals were academic $(n=10,55.6 \%)$, large ( $\geq 500$ beds) $(n=10,55.6 \%)$ and located in urban settings $(n=9,50.0 \%)$. Of the 53 team members who reported their profession $(96.4 \%)$, the majority worked in pharmacy $(\mathrm{n}=31,58.3 \%)$, followed by medicine $(\mathrm{n}=13,24.5 \%)$ (table 1). Nursing and other professions were grouped together due to small samples. The other
Table 1 Characteristics of the study hospitals and individual respondents

\begin{tabular}{ll}
\hline & $\mathbf{n}(\%)$ \\
\cline { 2 - 2 } Hospital level & $\mathbf{N}=18$ \\
\hline Hospital type & $10(55.6)^{\star}$ \\
Community & $8(44.4)$ \\
Academic & \\
Hospital size (number of beds) & $3(16.7)$ \\
$\leq 250$ & $5(27.8)$ \\
\hline $251-499$ & $10(55.6)$ \\
\hline Hospo0 & \\
\hline Urban & $9(50.0)$ \\
\hline Suburban & $7(38.9)$ \\
\hline Rural & $2(11.1)$ \\
\hline Individual level & $\mathbf{N}=52$ \\
\hline Profession & \\
\hline Pharmacy $\dagger$ & $30(27.7)$ \\
\hline Medicineł & $13(25.0)$ \\
\hline Nursing & $3(5.8)$ \\
\hline Other§ & $6(11.5)$ \\
\hline
\end{tabular}

*Includes one Veterans Affairs hospital and one safety net hospital. †Includes pharmacists and pharmacy residents and interns. †Includes internal medicine physicians and hospitalists. $\S$ The 'Other' category includes patient safety officers and quality improvement staff members.

professions included QI staff, patient safety officers, clinical informatics and occupational therapy.

\section{Contextual factors}

There was a statistically significant difference among the contextual factor scores by domain $(\mathrm{p}<0.001$, table 2$)$. Organisational capacity was given the lowest rating on average (mean $=4.0$ of a possible 7.0 ) and was statistically significantly lower than the average ratings for all of the other contextual factors (Bonferroni-corrected $\mathrm{p}<0.001$ ). On the other hand, perceived team cohesion and goal

Table 2 Hospital-level contextual factor ratings $(\mathrm{N}=18)$

\begin{tabular}{ll}
\hline Contextual factors & Mean (SD) \\
\hline Organisational structures & \\
Organisational capacity & $4.0(1.1)$ \\
Leadership support & $5.4(0.8)$ \\
Goal alignment & $6.0(0.5)$ \\
Organisational processes & \\
Staff involvement & $5.5(0.6)$ \\
Patient safety climate & $5.3(0.5)$
\end{tabular}

Team characteristics

Perceived team cohesion $6.2(0.5)$ 
Table 3 Summaries of contextual factors by hospital characteristics $(\mathrm{N}=18)^{\star}$

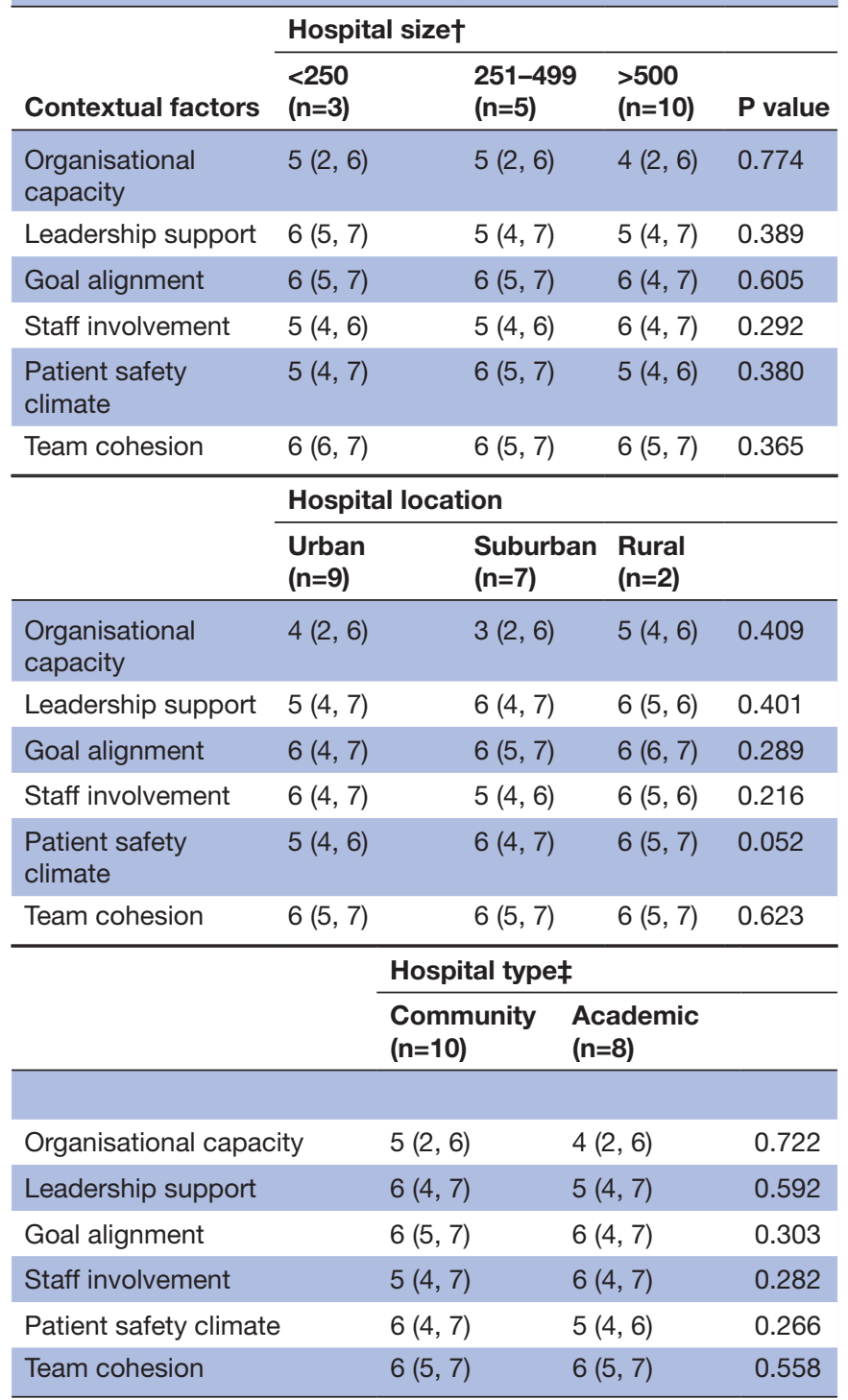

*Values in the cells are median (min, max).

tHospital size reported as number of beds.

$\ddagger$ Teaching hospitals as members of the Council of Teaching Hospitals and Health Systems.

alignment were given the highest ratings on average (mean 6.0 of a possible 7.0). In addition to organisational capacity, those ratings were statistically significantly higher than the average ratings for both of the organisational processes of staff involvement and patient safety climate (mean $=5.5$ and 5.3, respectively; Bonferronicorrected $\mathrm{p}<0.05)$ (table 2).

\section{Contextual factors by hospital characteristics}

Summaries of contextual factor scores by hospital size, location and type are shown in table 3. No statistically significant differences were observed by hospital characteristic $(\mathrm{p}>0.05)$.
Table 4 Comparison of contextual factors by groups of respondents $(\mathrm{N}=53)$

\begin{tabular}{|c|c|c|c|c|}
\hline \multirow[b]{2}{*}{ Contextual factors } & \multicolumn{3}{|c|}{$\begin{array}{l}\text { Profession (values in the cells are } \\
\text { median (min, max) }\end{array}$} & \multirow[b]{2}{*}{$P$ value } \\
\hline & $\begin{array}{l}\text { Pharmacy } \\
(\mathrm{N}=30)\end{array}$ & $\begin{array}{l}\text { Medicine } \\
(\mathrm{N}=13)\end{array}$ & $\begin{array}{l}\text { Nursing/ } \\
\text { other }(\mathrm{N}=9)\end{array}$ & \\
\hline $\begin{array}{l}\text { Organisational } \\
\text { capacity }\end{array}$ & $4(2,6)$ & $4(1,7)$ & $4(3,5)$ & 0.917 \\
\hline Leadership support & $6(4,7)^{*} \dagger$ & $6(4,7)$ & $6(5,7)^{\star} \dagger$ & 0.026 \\
\hline Goal alignment & $6(4,7)$ & $6(5,7)$ & $6(5,7)$ & 0.828 \\
\hline Staff involvement & $6(4,7)$ & $6(4,7)$ & $6(4,7)$ & 0.774 \\
\hline Patient safety climate & $5(4,7)$ & $5(4,7)$ & $6(4,7)$ & 0.335 \\
\hline Team cohesion & $6(4,7)$ & $6(6,7)$ & $7(4,7)$ & 0.701 \\
\hline
\end{tabular}

${ }^{*}$ Reported lower leadership support than did nursing/other team members. $\dagger($ Bonferroni corrected $\mathrm{p}<0.05)$.

\section{Contextual factors by implementation team members' profession}

Summaries of the contextual factor scores by implementation team members' profession are shown in table 4. Respondents in the pharmacy profession gave lower ratings of leadership support than did those in the nursing or other professions group $(\mathrm{p}=0.026)$. While the median values were the same (6), all but one of the nursing and other professional group ( 8 of 9) gave values of 6 or higher of the possible 7 points while only $53 \%$ (16 of 30) in the pharmacy group gave scores of 6-7.

\section{DISCUSSION}

In this study of 18 sites participating in a multi-centre QI initiative, we found differences in the ratings of six contextual factors that could affect implementation, and ratings did not differ by hospital characteristics such as size, type and location. Of all the organisational factors assessed in this study, implementation teams that participated in MARQUIS2 rated perceived team cohesion the highest (mean=6.2; $\mathrm{SD}=0.5$ ). This finding is important because when team cohesion is high, teams perform better and are more satisfied..$^{32}{ }^{41}$ Teams who perform better also achieve better patient outcomes. ${ }^{33}$ Recent research indicates that support from team members is an important facilitator while negative attitudes or beliefs about team members, in contrast, are significant barriers to implementation efforts. ${ }^{18}$ In our study, team members rated cohesion high when preparing for full-scale implementation, which likely enhanced the overall implementation efforts in some participating hospitals. As we did not assess cohesion during the active implementation period in our 18 hospitals, further research is necessary to clarify whether cohesion persists over time during MedRec implementation efforts. This result is important because MedRec involves many clinical personnel, and QI teams need to reflect that diversity, so it is reassuring that the multidisciplinary nature of these teams did not degrade cohesion. Nevertheless, QI teams need to stay vigilant regarding cohesion, because professional boundaries 
and status differences within teams have the potential to impact team effectiveness ${ }^{33}$ which can inhibit overall implementation processes, even when a supportive organisational context is present.

This study also found excellent alignment of the goals behind the implementation of MedRec interventions and the overall goals, mission and vision of hospitals. Previous research has indicated that interventions that demonstrate good applicability and relevance to the clinical setting and fit with the organisation's mission, priorities and values are more likely to be successfully implemented. ${ }^{24-26} 42$ Goal alignment is important because it enhances buy-in from staff members and helps to create a shared vision of the importance and benefits of the intervention. Therefore, to enhance implementation efforts, organisational leaders must clearly articulate the goals behind MedRec implementation and indicate how it aligns with the broader organisational goals. For example, the value of MedRec improving patient safety and reducing medication errors (that could, eg, increase length of stay or lead to readmissions) should be emphasised. ${ }^{43}$

In this study, participants rated leadership support as high (mean $=5.4, \mathrm{SD}=0.8$ ) followed by staff involvement (mean $=5.5, \mathrm{SD}=0.6$ ). In contrast, organisational capacity was rated the lowest. Previous MedRec studies recognised the importance of strong leadership to create an institution-wide awareness and commitment to medication safety. ${ }^{44}$ Staff involvement in the planning and execution of the implementation of interventions facilitates staff buy-in and support and is an important facilitator of implementation and long-term sustainment. Staff involvement enhances shared decision-making and commitment to the implementation of interventions and fosters trust and open communication, factors considered important facilitators of successful implementation. ${ }^{18}{ }^{45}$ Conversely, implementation efforts have been hampered across US hospitals by limited resources in staff and time, ${ }^{44}{ }^{46}$ and this study similarly demonstrated that the organisational capacity of MARQUIS2 hospitals' to support MedRec implementation was limited.

In contrast to previous research, our study did not find statistically significant differences in contextual factors by hospital size, type, or location or team members' profession in hospitals that participated in this multi-site QI work. Our findings do not support the notion that small, rural hospitals necessarily have limited resources compared with their larger, urban counterparts. Moreover, academic hospitals were like community hospitals regarding contextual factors. One reason for the possible difference in study findings compared with previous research is that hospitals selected to participate in MARQUIS2 needed to have a certain level of QI infrastructure and consider MedRec a priority area in order to be enrolled in the study. Although the contextual factors such as organisation capacity and patient safety climate were not formally measured as part of the application process, it is possible that the site selection procedures resulted in a sample of hospitals that had similar contextual factors. Future research should focus on conducting a similar study using a larger and more heterogeneous sample of facilities. Research in this area would help to clarify whether multi-site QI work should be tailored to be specific to a hospital's characteristics or more directly to the sites' contextual factors, regardless of their other characteristics. We anticipate such tailoring would require an assessment of the local context when preparing for implementation to allow for a personalised approach. Additional work is currently underway to further elucidate the role of hospital characteristics and organisational context in the selection of implementation strategies, implementation success (eg, number of systemlevel interventions adopted, proportion of patients that received patient-level interventions) and intervention sustainability over time; this will allow for future tailoring of implementation processes to the local implementation context.

Increasingly, hospitals are utilising pharmacy services (ie, pharmacists and pharmacy technicians) to streamline their MedRec programme as evidence suggests fewer unintentional discrepancies when pharmacists conduct MedRec. ${ }^{47}$ We found that pharmacists perceived leadership support lower than nursing and other professions. Leadership support is essential to successful MedRec implementation, by allocating resources (ie, funding and personnel) and helping to remove system barriers. ${ }^{48}$ Why pharmacists in the study felt less supported by leadership is unclear. However, subsequent research with MARQUIS2 hospitals indicated that hiring additional pharmacy staff was not always possible in participating hospitals, which placed additional workload burden on existing pharmacy staff. In addition, in some hospitals pharmacists acted as site leaders and often sought to obtain resources like staff and time to execute the project, sometimes without success. The lack of additional resources coupled with the pressure to successfully execute MARQUIS toolkit implementation likely added additional strain and perceptions of limited leadership support at many sites. Other studies of pharmacist job satisfaction have found a positive association between job satisfaction and adequate staffing and that pharmacists often feel unsupported by management in general, whether due to lack of resources or for other reasons. ${ }^{4950}$

\section{Study limitations}

This study was conducted in the 18 hospitals that participated in MARQUIS2, but the sample size was limited and lacked statistical power to detect small differences among hospitals. Second, the study was limited to an analysis of contextual factors at the organisational level. Contexts can vary greatly, not only between hospitals, but at the more micro-level (eg, hospital units, unit-level staff) and more macro-level (eg, countries) ${ }^{51-53}$ Third, given that our population was limited to hospitals that participated in MARQUIS2, the generalisability of our study findings may be limited. The hospitals were diverse in size, type and location, but they had all been selected to participate in a 
QI intervention. Thus, the hospitals may have been inherently different from other US hospitals that did not apply to or were not accepted to MARQUIS2. Those potential differences were not measured. Fourth, the study is also limited by the use of a self-report survey, which increased the risk for response bias and social desirability bias in participant responses. Furthermore, the response rate was on the low end of acceptability at $66 \%$ and we have no information available regarding the non-responders that would allow us to assess the generalisability of our findings to the MARQUIS2 population. This risk was mitigated by ensuring the confidentiality of participants throughout the research process and formulating questions that were easy to understand. Despite these limitations, hospitals that wish to implement MedRec interventions can learn important lessons, including the need for leadership support, building organisational capacity to support implementation and involving staff in the implementation of QI initiatives.

\section{Next steps}

This paper is the first in a series of papers investigating the role of organisational context in the implementation of MedRec interventions. Current work is underway to link the contextual findings discussed in this paper to organisational readiness for change and implementation success by sites. Furthermore, future work will aim to explore linkages between contextual factors and strategies hospitals used to implement the MARQUIS toolkit.

\section{CONCLUSION}

The context of hospitals participating in a national mentored MedRec QI study was similar in the early stages of implementation despite variation in hospital size, type and location. These hospital characteristics may thus not be as an important consideration as previously thought when multi-site QI initiatives are undertaken. Furthermore, the cohesion of implementation teams early in the MARQUIS2 initiative was high and did not differ by the profession of team members. Therefore, the use of an interdisciplinary team, which has many advantages, did not appear to degrade cohesion. Finally, pharmacy services may need additional leadership support during MedRec QI efforts.

\section{Author affiliations}

${ }^{1}$ School of Nursing, Vanderbilt University, Nashville, Tennessee, USA

${ }^{2}$ Vanderbilt Center for Clinical Quality and Implementation Research, Vanderbilt University Medical Center, Nashville, TN, United States

${ }^{3}$ Department of Medicine, Brigham and Women's Hospital, Boston, Massachusetts, USA

${ }^{4}$ Department of Medicine, Harvard Medical School, Boston, Massachusetts, USA

${ }^{5}$ Section of Hospital Medicine, Division of General Internal Medicine and Public Health, Vanderbilt University School of Medicine, Vanderbilt University Medical Center, Nashville, Tennessee, USA

${ }^{6}$ Geriatric Research Education and Clinical Centers, VA Tennessee Valley Healthcare System Nashville Campus, Nashville, Tennessee, USA

${ }^{7}$ School of Medicine, Vanderbilt University Medical Center, Nashville, Tennessee, USA
Acknowledgements We acknowledge the support and hard work of Megan Mallouk and staff at the Society of Hospital Medicine and the quality improvement experts who served as mentors of hospital sites during the MARQUIS2 study and supported work in these hospitals.

Contributors DPS conceptualised the study, and DPS, MD and SK led the study design. DPS lead the data acquisition, with support from JLS, ASM and SK. DPS and MD planned the data analysis with support from SK and JLS. DPS, MD and SK led interpretation of the results, with input from JLS and ASM. DPS drafted the manuscript, with support from SK. All authors provided feedback and approved the final version of the manuscript.

Funding This project was partially supported by funding from AHRQ (K01HS2548601) and the CTSA grant (UL1 TR000445) from NCATS/NIH.

Competing interests None declared.

Patient consent for publication Not required.

Ethics approval The study protocol was approved by the University Institutional Review Board.

Provenance and peer review Not commissioned; externally peer reviewed. Data availability statement Data are available upon reasonable request.

Open access This is an open access article distributed in accordance with the Creative Commons Attribution Non Commercial (CC BY-NC 4.0) license, which permits others to distribute, remix, adapt, build upon this work non-commercially, and license their derivative works on different terms, provided the original work is properly cited, appropriate credit is given, any changes made indicated, and the use is non-commercial. See: http://creativecommons.org/licenses/by-nc/4.0/.

ORCID iD

Deonni P Stolldorf http://orcid.org/0000-0002-1352-5397

\section{REFERENCES}

1 Belda-Rustarazo S, Cantero-Hinojosa J, Salmeron-García A, et al. Medication reconciliation at admission and discharge: an analysis of prevalence and associated risk factors. Int J Clin Pract 2015;69:1268-74.10.1111/ijcp.12701

2 Lee A, Varma A, Boro M, et al. Value of pharmacist medication interviews on optimizing the electronic medication reconciliation process. Hosp Pharm 2014;49:530-8.

3 Varsi C, Ekstedt M, Gammon D, et al. Using the consolidated framework for implementation research to identify barriers and facilitators for the implementation of an Internet-based patientprovider communication service in five settings: a qualitative study. $J$ Med Internet Res 2015;17:e262.

4 Greenwald JL, Halasyamani L, Greene J, et al. Making inpatient medication reconciliation patient centered, clinically relevant and implementable: a consensus statement on key principles and necessary first steps. J. Hosp. Med. 2010;5:477-85.

5 Gardner KL, Dowden M, Togni S, et al. Understanding uptake of continuous quality improvement in Indigenous primary health care: lessons from a multi-site case study of the audit and best practice for chronic disease project. Implementation Sci 2010;5.

6 Stolldorf DP, Havens DS, Jones CB. Sustaining innovations in complex health care environments: a multiple-case study of rapid response teams. J Patient Saf 2016. doi:10.1097/ PTS.0000000000000239. [Epub ahead of print: 11 Jan 2016].

7 Stolldorf DP. Sustaining health care interventions to achieve quality care: what we can learn from rapid response teams. J Nurs Care Qual 2017;32:87-93.

8 Mancini JA, Marek LI. Sustaining community-based programs for families: conceptualization and measurement. Fam Relat 2004;53:339-47.

9 Mueller SK, Sponsler KC, Kripalani S, et al. Hospital-Based medication reconciliation practices: a systematic review. Arch Intern Med 2012;172:1057-69.

10 Salanitro AH, Kripalani S, Resnic J, et al. Rationale and design of the multicenter medication reconciliation quality improvement study (Marquis). BMC Health Serv Res 2013;13:230.

11 Effects of a refined evidence-based toolkit on medication reconciliation quality and safety at multiple hospitals: results of the MARQUIS2 study. Society of Hospital Medicine Annual Conference, 2019.

12 Schnipper JL, Mixon A, Stein J, et al. Effects of a multifaceted medication reconciliation quality improvement intervention on 
patient safety: final results of the Marquis study. BMJ Qual Saf 2018;27:954-64.

13 Kennelty KA, Chewning B, Wise M, et al. Barriers and facilitators of medication reconciliation processes for recently discharged patients from community pharmacists' perspectives. Res Social Adm Pharm 2015;11:517-30.

14 Stolldorf DP, Mion LC, Jones CB. A survey of hospitals that participated in a statewide collaborative to implement and sustain rapid response teams. J Healthc Qual 2016;38:202-12.

15 Gotlib Conn L, McKenzie M, Pearsall EA, et al. Successful implementation of an enhanced recovery after surgery programme for elective colorectal surgery: a process evaluation of champions' experiences. Implementation Sci 2015;10.

16 Benn J, Burnett S, Parand A, et al. Studying large-scale programmes to improve patient safety in whole care systems: challenges for research. Soc Sci Med 2009;69:1767-76.

17 Gleason KM, McDaniel MR, Feinglass J, et al. Results of the medications at transitions and clinical handoffs (match) study: an analysis of medication reconciliation errors and risk factors at hospital admission. J Gen Intern Med 2010;25:441-7.

18 Allison JJet al. Relationship of hospital teaching status with quality of care and mortality for Medicare patients with acute MI. JAMA 2000;284:1256-62.

19 Hagedorn HJ, Heideman PW. The relationship between baseline organizational readiness to change assessment subscale scores and implementation of hepatitis prevention services in substance use disorders treatment clinics: a case study. Implementation Sci 2010;5.

20 Sorra J, Nieva V. Psychometric analysis of the hospital survey on patient safety. final report to Agency for Healthcare Research and Quality (AHRQ) Washington: AHRQ (prepared by Westat, under contract to BearingPoint, and delivered to the Agency for Healthcare Research and Quality [AHRQ], under Contract No 29-96-0004. Rockville MD: Agency for Healthcare Research and Quality, 2003.

21 Kripalani S, Jackson AT, Schnipper JL, et al. Promoting effective transitions of care at hospital discharge: a review of key issues for hospitalists. J. Hosp. Med. 2007;2:314-23.

22 Chin WW, Salisbury WD, Pearson AW, et al. Perceived cohesion in small groups: adapting and testing the perceived cohesion scale in a small-group setting. Small Group Res 1999;30:751-66.

23 Mickan S, Burls A, Glasziou P. Patterns of 'leakage' in the utilisation of clinical guidelines: a systematic review. Postgrad Med $J$ 2011;87:670-9.

24 Feldman LS, Costa LL, Feroli ER, et al. Nurse-pharmacist collaboration on medication reconciliation prevents potential harm. $J$ Hosp Med 2012;7:396-401.

25 Hartmann T. Goal and process alignment during the implementation of decision support systems by project teams. J. Constr. Eng. Manage. 2011;137:1134-41

26 Lepmets M, McBride T, Ras E. Goal alignment in process improvement. J Syst Softw 2012;85:1440-52.

27 Vogelsmeier A, Pepper GA, Oderda L, et al. Medication reconciliation: a qualitative analysis of clinicians' perceptions. Res Social Adm Pharm 2013:9:419-30.

28 Mendes AE, Lombardi NF, Andrzejevski VS, et al. Medication reconciliation at patient admission: a randomized controlled trial. Pharm Pract 2016;14:656.

29 Hessels AJ, Agarwal M, Saiman L, et al. Measuring patient safety culture in pediatric long-term care. J Pediatr Rehabil Med 2017;10:81-7.

30 Tekleab AG, Quigley NR, Tesluk PE. A longitudinal study of team conflict, conflict management, cohesion, and team effectiveness. Group \& Organization Management 2009;34:170-205.

31 Proudlove NC, Samarasinghe BSW, Walshe K. Investigating consistent patterns of variation in short-notice cancellations of elective operations: the potential for learning and improvement through multi-site evaluations. Health Serv Manage Res 2018;31:111-9.

32 Krein SL, Damschroder LJ, Kowalski CP, et al. The influence of organizational context on quality improvement and patient safety efforts in infection prevention: a multi-center qualitative study. Soc Sci Med 2010;71:1692-701.

33 Steeb D, Webster L, et al, American Pharmacists Association. Improving care transitions: optimizing medication reconciliation. $J$ Am Pharm Assoc 2012;52:e43-52.

34 Powell BJ, Waltz TJ, Chinman MJ, et al. A refined compilation of implementation strategies: results from the expert recommendations for implementing change (ERIC) project. Implementation Sci 2015;10.

35 Huijg JM, Gebhardt WA, Dusseldorp E, et al. Measuring determinants of implementation behavior: psychometric properties of a questionnaire based on the theoretical domains framework. Implementation Sci 2014;9.10.1186/1748-5908-9-33

36 O'Loughlin J, Renaud L, Richard L, et al. Correlates of the sustainability of community-based heart health promotion interventions. Prev Med 1998;27:702-12.

37 Annual research meeting. Organizational context in the implementation of medication reconciliation. New Orleans, LA: Annual research meeting 2017, 2017.

38 Waltz CF, Strickland OL, Lenz ER. Measurement in nursing and health research. Springer Publishing Company, 2016.

39 Benn J, Burnett S, Parand A, et al. Factors predicting change in hospital safety climate and capability in a multi-site patient safety collaborative: a longitudinal survey study. BMJ Qual Saf 2012;21:559-68.

40 Salisbury WD, Carte TA, Chidambaram L. Cohesion in virtual teams: validating the perceived cohesion scale in a distributed setting. SIGMIS Database 2006;37:147-55.

41 Mach M, Dolan S, Tzafrir S. The differential effect of team members' trust on team performance: the mediation role of team cohesion. $J$ Occup Organ Psychol 2010;83:771-94.

42 Arroyave AM, Penaranda EK, Lewis CL. Organizational change: a way to increase colon, breast and cervical cancer screening in primary care practices. J Community Health 2011;36:281-8.

43 Kripalani Set al. Effect of a pharmacist intervention on clinically important medication errors after hospital discharge. Ann Intern Med 2012;157:1.

44 van Sluisveld N, Zegers M, Natsch S, et al. Medication reconciliation at hospital admission and discharge: insufficient knowledge, unclear task reallocation and lack of collaboration as major barriers to medication safety. BMC Health Serv Res 2012;12:170.

45 Carmona F, Manso PH, Ferreira MN, et al. Collaborative quality improvement in the congenital hear defects: development of the assist Consortium and a preliminary surgical outcomes report. Braz $J$ Cardiovasc Surg 2017;32:260-9.

46 Sanchez SH, Sethi SS, Santos SL, et al. Implementing medication reconciliation from the planner's perspective: a qualitative study. BMC Health Serv Res 2014;14:290.

47 Mekonnen AB, McLachlan AJ, Brien J-anneE. Effectiveness of pharmacist-led medication reconciliation programmes on clinical outcomes at hospital transitions: a systematic review and metaanalysis. BMJ Open 2016;6:e010003.

48 Lau R, Stevenson F, Ong BN, et al. Achieving change in primary care-causes of the evidence to practice gap: systematic reviews of reviews. Implementation Sci 2015;11.

49 Kuiper RL, Cowan DLP, Pacitti R. Job satisfaction in hospital pharmacists. Am J Health Syst Pharm 2011;68:115-15.

50 Liu CS, White L. Key determinants of hospital pharmacy staff's job satisfaction. Res Social Adm Pharm 2011;7:51-63.

51 Bragadóttir H, Kalisch BJ, Tryggvadóttir GB. Correlates and predictors of missed nursing care in hospitals. J Clin Nurs 2017;26:1524-34.10.1111/jocn.13449

52 Baernholdt M, Jennings BM, Lewis EJ. A pilot study of staff Nurses' perceptions of factors that influence quality of care in critical access hospitals. J Nurs Care Qual 2013;28:352-9.

53 Braithwaite J, Herkes J, Ludlow K, et al. Association between organisational and workplace cultures, and patient outcomes: systematic review. BMJ Open 2017;7:e017708.10.1136/ bmjopen-2017-017708 